\title{
Marking aspect along a scale: The semantics of -te iku and -te kuru in Japanese*
}

\author{
Yusuke Kubota \\ University of Tokyo, JSPS
}

\begin{abstract}
This paper proposes an analysis of two aspectual markers -te $i k u$ and -te kuru in Japanese within a scale-based approach to semantics, focusing on cases in which they occur with degree achievements (or incremental change of state predicates). It will be shown that the complex telicity and entailment patterns that these aspectual markers exhibit when they occur with degree achievements in Japanese can be explained by analyzing them as operators that change the scale structures of the predicates that they take as arguments.
\end{abstract}

Keywords: scale structure, aspectual composition, telicity, degree achievement, change of state predicate, Japanese

\section{Introduction}

There is now a rapidly growing body of work on aspectual composition from scalebased approaches to semantics (cf., e.g., Kennedy \& Levin 2008; Piñón 2008; Beavers 2010). As shown by Kennedy \& Levin (2008) (K\&L), this approach is especially effective for capturing the properties of predicates that show incremental changes of states such as degree achievements (DAs), which have long been known to be problematic for previous theories of aspect and telicity. While K\&L's results are highly successful and promising, as the authors themselves note, the empirical scope is so far limited to DAs in English. The goal of this paper is to extend the cross-linguistic coverage of this scale-based approach to aspectual composition by proposing an analysis of two aspectual markers -te iku and -te kuru in Japanese.

Iku means 'go' and kuru means 'come' when used as main verbs. As aspectual markers, these verbs syntactically combine with verbs marked with the morpheme -te; semantically, both -te iku and -te kuru have several related but distinct uses (cf.,

* I would like to thank Wataru Uegaki for patiently listening to my bad ideas and incorrect analyses (which I have eventually abandoned), as well as for insightful remarks both on data and analysis. Thanks also to the following people for their comments, suggestions and encouragements: Takane Ito, Chris Kennedy, Ai Matsui, Osamu Sawada and Shûichi Yatabe. All of the remaining errors are mine. This work is supported by the Research Fellowship of the Japan Society for the Promotion of Science under Grant No. 22-2912.

C2010 Yusuke Kubota 
e.g., Imani 1990; Kinsui 2000; Watanabe 2008). In this paper, I will focus on the uses of these aspectual markers when they occur with DAs, that is, verbs such as sameru 'cool', hirogaru 'widen', and katamuku 'slant', which denote (typically) gradual, incremental changes of states. An example is given in (1):

(1) Oyu-ga same-te it-ta/ki-ta.

hot.water-NOM cool-TE IKU-PAST/KURU-PAST

'The (hot) water came to be cool(er).'

As we will see below, -te iku and -te kuru exhibit somewhat complex entailment and telicity patterns when they occur with DAs. These facts have largely gone unnoticed in the previous literature and there is as yet no formal analysis of these aspectual markers that captures these properties adequately. After reviewing the data, I will propose a scale-based analysis of -te iku and -te kuru, building on recent scalebased approaches to event semantics. It will be shown that the apparently complex and puzzling properties of these aspectual markers all fall out straightforwardly once a proper analysis is formulated which recognizes the scale-sensitive properties of these expressions appropriately.

\section{$2-$-Te iku and -te kuru with degree achievements}

\subsection{Entailment patterns}

Unlike in English, DAs in Japanese entail that the positive form of the corresponding adjective (or stative predicate) is true in the result state, regardless of the scale structure of the predicate. Sameru 'cool' in (2) is an open-scale predicate, katamuku 'slant' in (3) is a minimum standard predicate and husagaru 'close' in (4) is a maximum standard predicate, but all uniformly induce uncancellable change of state entailments: ${ }^{1,2,3}$

1 In this sense, calling these verbs 'degree achievements' might be a bit misleading given that the term is standardly associated with a class of verbs that are like achievements but which (unlike typical achievements) lack definite change of state entailments. However, for want of a better term, I keep calling these verbs in Japanese 'degree achievements' below.

2 I assume that verbal predicates in Japanese have the same scale structures as the corresponding adjectives (as will become clear below, this assumption is crucial for the proper analysis of DAs in Japanese). 'Minimum standard predicates' and 'maximum standard predicates' (terms from Kennedy (2007)) are predicates whose meanings are determined with respect to scales with minimum and maximum endpoints, respectively. The scale structures of adjectives can be tested with the ordinary tests such as coocurrence restrictions with degree modifiers such as wazukani 'slightly' (compatible only with minimum standard predicates) and kanzenni 'totally' (compatible only with maximum standard predicates).

3 In this paper, I focus on intransitive verbs that denote incremental changes of states. Many of these verbs have transitive counterparts (e.g. atatameru 'make something warm/warmer', hirogeru 'make 
(2) Oyu-ga same-ta. \#Daga, mada same-te i-nai. hot.water-NOM cool-PAST but yet cool-TE be-NEG intended: 'The hot water cooled, but it isn't cool yet.'

(open-scale)

(3) Too-ga katamui-ta. \#Daga, mada katamui-te i-nai. tower-NOM lean-PAST but yet slant-TE be-NEG. intended: 'The tower got slanted, but it isn't slanted yet.' (min standard)

(4) Ana-ga husagat-ta. \#Daga, mada husagat-te i-nai. Hole-NOM close-PAST but yet close-TE be-NEG intended: 'The hole got closed, but it isn't closed yet.'

(max standard)

When occurring with DAs, both -te iku and -te kuru mean gradual changes of states along the relevant scale. This has effects on the entailment patterns of the sentences. Specifically, as shown in (5)-(7), with both -te iku and -te kuru, the entailment to the positive form disappears for open-scale and maximum standard predicates:

Oyu-ga same-te it-ta/ki-ta. Daga, mada same-te i-nai. hot.water-NOM cool-TE IKU-PAST/KURU-PAST but yet cool-TE be-NEG

'The (hot) water came to be cooler, but it isn't cool yet.'

\#Too-ga katamui-te it-ta/ki-ta. Daga, mada katamui-te
Tower-NOM lean-TE IKU-PAST/KURU-PAST but yet slant-TE
i-nai.
be-NEG
'The tower came to be slanted, but it isn't slanted yet.'

Ana-ga husagat-te it-ta/ki-ta. Daga, mada husagat-te i-nai.
Hole-NOM close-TE IKU-PAST/KURU-PAST but yet close-TE be-NEG

'The hole came to be closed, but it isn't closed yet.'

Despite (apparently) the same entailment effects, -te iku and -te kuru in (5)-(7) mean somewhat different things. First, (5) (open-scale predicate) with -te kuru is felicitous only when the water becomes relatively cool, undergoing some substantial change of degree from the initial state. Thus, (5) with -te kuru (but not with -te iku) is infelicitous for describing a change of degree from $80^{\circ} \mathrm{C}$ to $75^{\circ} \mathrm{C}$. Second, (6) (minimum standard predicate) with -te kuru is felicitous only when the object in

something wide/wider'). The transitive variants (at least those whose corresponding adjectives have open scales) have different aspectual properties than their intransitive counterparts in that they are atelic predicates (Sugioka 2009) and do not seem to induce the entailments to the positive form in the result state (at least not as strongly as the intransitive variants). Why this is the case is an interesting and important question, but I leave detailed considerations of the transitive variants of DAs for future study. 
Marking aspect along a scale: -Te iku and -te kuru in Japanese

question has no degree of bend initially, whereas no such constraint is present with -te iku. In what follows, I call this requirement the 'initial zero degree requirement'. Importantly, this requirement exists for the unmarked form of minimum standard predicates (= (3)) as well. Finally, (7) (maximum standard predicate) with -te kuru entails that the object in question ends up coming close to the maximum endpoint (but not reaching it), but -te iku is neutral about the amount of degree change (it could be that the degree change is slight; it could also be that the maximum endpoint is reached).

\subsection{Telicity}

Since Japanese DAs are change of state predicates, they are uniformly telic (regardless of the scale structure of the corresponding adjective) (Sugioka 2009). This can be tested with the standard test for telicity with 'in' and 'for' adverbials: ${ }^{4}$

$$
\begin{aligned}
& \text { Sanzyup-pun??(-de) oyu-ga same-ta. } \\
& \text { 30-minute(-in) hot.water-NOM cool-PAST } \\
& \text { 'The hot water became cool in/??for } 30 \text { minutes.' }
\end{aligned}
$$

$$
\begin{array}{ll}
\text { Sanzyuu-nen??(-de) too-ga katamui-ta. } \\
\text { 30-year(-in) } & \text { tower-NOM lean-PAST }
\end{array}
$$

'The tower became slanted in/??for 30 years.'

$$
\begin{aligned}
& \text { Mik-ka-kan??(-de) ana-ga husagat-ta. } \\
& \text { 3-day(-in) hole-NOM close-PAST } \\
& \text { 'The hole closed in/??for } 30 \text { days.' }
\end{aligned}
$$

-Te kuru and -te iku affect the telicity of the predicates they attach to. The general pattern is that -te kuru-marked predicates are telic whereas -te $i k u$-marked ones are atelic. There is, however, one important exception: -te iku-marked maximum standard predicates exhibit variable telicity of the kind found with English DAs. In what follows, I will test the telicity of -te kuru and -te iku-marked DAs with the standard test for telicity with 'in' and 'for' adverbials.

Except with maximum standard predicates, -te $i k u$-marked DAs are atelic and allow only for 'for' adverbials: ${ }^{5}$

$$
\begin{aligned}
& \text { Sanzyup-pun(*-de) oyu-ga } \quad \text { same-te it-ta. } \\
& \text { 30-minute(-in) hot.water-NOM cool-TE IKU-PAST } \\
& \text { 'The water got cooler for } 30 \text { min.' }
\end{aligned}
$$

4 Same results can be obtained with other tests such as the progressive vs. perfect ambiguity in the -te iru form, but I omit the data due to space limitations.

5 Actually, (11)-(13) with 'in' adverbials aren't completely unacceptable, but the only available readings for them are inchoative ones, which are irrelevant here. 
(12) Sanzyuu-nen(*-de) too-ga katamui-te it-ta.

30-year(-in) tower-NOM lean-TE IKU-PAST

'The tower kept leaning for 30 years.'

(13) Mik-ka-kan?(?-de) ana-ga husagat-te it-ta.

3-day(-in) hole-NOM close-TE IKU-PAST

'The hole closed for/in 3 days.'

Note the exceptional pattern in (13). Unlike with open-scale and minimum standard predicates, maximum standard predicates marked with -te $i k u$ are somewhat exceptional here in that they allow for both 'in' adverbials and 'for' adverbials. This might initially appear puzzling, but the analysis that I will propose in the next section correctly predicts this fact.

The patterns with -te kuru-marked predicates are simpler. Despite the loss of entailment to the positive form for some predicates observed above (cf. (5)-(7)), -te kuru does not change the telicity of DAs in Japanese, which are uniformly telic regardless of the scale structure of the corresponding adjective. As shown in (14)(16), -te kuru-marked DAs allow only for 'in' adverbials, suggesting that they are all telic predicates:

(14) Sanzyup-pun*(-de) oyu-ga same-te ki-ta. 30-minute(-in) hot.water-NOM cool-TE KURU-PAST

'The water became cool in 30 min.'

Sanzyuu-nen*(-de) too-ga katamui-te ki-ta.

30-year(-in) tower-NOM lean-TE KURU-PAST

'The tower became slanted in 30 years.'

(16) Mik-ka-kan*(-de) ana-ga husagat-te ki-ta.

3-day(-in) hole-NOM close-TE KURU-PAST

'The hole got closed in 3 days.'

\section{Analysis}

In this section, I propose an analysis of -te iku and -te kuru that accounts for the facts observed in the previous section. We will see that the key to a successful analysis of the apparently complex set of facts observed above is to recognize the systematic pattern in which the meanings of these aspectual markers interact with the scale structures of the predicates that they attach to. 
Marking aspect along a scale: -Te iku and -te kuru in Japanese

\subsection{Degree achievements in Japanese}

Since my analysis of Japanese DAs builds on the scale-based analysis of DAs in English by K\&L, I will start by reviewing their analysis briefly. K\&L's analysis of English DAs builds on the analysis of gradable adjectives by Kennedy \& McNally (2005), which recognizes two parameters in capturing the meanings of (adjectival) gradable predicates: scale structure and standard of comparison. According to Kennedy \& McNally (2005), gradable adjectives fall into two categories depending on the way in which their meanings are determined: relative adjectives such as tall and interesting express meanings that are dependent on contextually determined vague standards whereas absolute adjectives such as bent/straight and pure/impure express meanings that refer to context-independent fixed standards, which correspond to the (maximum or minimum) endpoints of the scale. Absolute adjectives are further classified into minimum standard adjectives (such as bent and pure) and maximum standard adjectives (such as straight and impure), which respectively refer to minimum and maximum endpoints of the relevant scale. Thus, the sentence The rod is bent is true just in case the degree of bend of the rod is above the minimum endpoint (i.e., the 'zero point'), and, conversely, The rod is straight is true just in case the rod is completely straight (that is, reaches the maximum endpoint). Kennedy \& McNally (2005) capture this pattern by analyzing the meanings of gradable adjectives by means of the notion of standard of comparison, which is sensitive to the scale structure of the adjective: adjectives with open scales involve context-dependent relative standards whose exact value is indeterminate; by contrast, for adjectives with closed scales, the standard is fixed to a context-independent absolute value, either the degree just above the minimum endpoint (for minimum standard predicates) or the degree corresponding to the maximum endpoint (for maximum standard predicates).

To be specific, following Kennedy (2007), I assume that adjectives denote measure functions of type $\langle e, d\rangle$ (where $d$ is the type for degrees) that map objects to the degrees that they possess on the relevant scale. With this assumption, we can analyze Japanese DAs as having scales whose structures are exactly identical to those for the corresponding adjectives (readers familiar with K\&L should note that this is different from their analysis of English DAs in not involving a derived scale; this assumption is crucial in capturing the differences between Japanese and English DAs). For example, verbs such as sameru 'cool' and hirogaru 'widen' denote measure functions that map objects to totally open scales, just like the corresponding adjectives. The only difference between verbal and adjectival predicates is that the former take event and time arguments in addition to the individual arguments. (17) shows the denotation for same 'cool':

$$
[\text { same }]=\lambda x \lambda e \lambda t \cdot \operatorname{coo}(x)(e)(t)
$$


This is a measure function (of type $\langle e,\langle e v,\langle i, d\rangle\rangle\rangle$ ) that takes an individual, an event and a time as arguments and returns the degree that the individual in question possesses on the scale of coolness in the specified event at the specified time.

This measure function combines with the verbal pos operator (an empty operator that converts a measure function to an ordinary predicate) in (18) to form a predicate of type $\langle e,\langle e v, t\rangle\rangle$.

$$
\left[\left[\operatorname{pos}_{v_{-} j p}\right]\right]=\lambda g \lambda x \lambda e: \underline{g(x)(e)(\operatorname{init}(e))<\operatorname{stnd}(g)} \cdot g(x)(e)(f i n(e)) \geq \operatorname{stnd}(g)
$$

This verbal pos operator introduces the presupposition (the underlined part) that the degree that the individual possesses at the initial state of the event is below the standard (where the notion of standard is understood in the above sense) and asserts that the degree at the final state of the event satisfies the standard. ${ }^{6}$

With these assumptions, the meaning of (2) (which involves the unmarked form of an open-scale DA same 'cool') is calculated as in (19): ${ }^{7}$

$$
\begin{aligned}
& {[[\text { oyu-ga same-ru }]]=\left[\left[\operatorname{pos}_{v_{-} j p}\right]\right]([[\text { same }]])([[\text { oyu }]])} \\
& =\lambda e: \operatorname{cool}(\mathbf{w})(e)(\operatorname{init}(e))<\operatorname{stnd}(\operatorname{cool}) \cdot \operatorname{cool}(\mathbf{w})(e)(\operatorname{fin}(e)) \geq \mathbf{s t n d}(\operatorname{cool}) \\
& =\lambda e \cdot \operatorname{cool}_{\mid}(\mathbf{w})(e) \geq \mathbf{s t n d}(\mathbf{c o o l}) \\
& \text { sameru 'become cool': . . . ---|-------*---|-- . . } \\
& \operatorname{init}(e) \quad f i n(e)
\end{aligned}
$$

Assuming that the event argument is existentially bound when the sentence is interpreted in the discourse, (19) is true just in case there is an event in which the coolness of the water at the initial state is below the standard (presupposition) and reaches the standard at the result state (assertion). In other words, the sentence is true just in case the water 'becomes cool'.

The important point here is that, since Japanese DAs refer to the standards associated with the corresponding adjectives when their truth conditions are calculated, the entailment to the positive form in the result state arises. This is indeed the correct result for sentences like (2). Note also that this analysis correctly predicts that sentences with maximum standard predicates (e.g. (4)) entail that the maximum endpoint is reached. This is so because the standard is set to the maximum endpoint

6 Note that, in this analysis, the denotations of the gradable predicate and the pos operator are essentially identical in adjectival predication and verbal predication. Given that there is less morpho-syntactic difference between adjectival predicates and verbal predicates in Japanese (where both types of predicates conjugate in the same paradigm) than in languages like English, one might then entertain the hypothesis that all gradable predicates in Japanese are inherently adjectival and that what I am calling 'degree achievements' in this paper are simply verbal (or eventive) uses of these adjectival predicates with the additional presuppositional restriction about the initial state of the event.

7 In the pictures here and below, $*$ designates the standard and + designates the endpoints of the scales. 
Marking aspect along a scale: -Te iku and -te kuru in Japanese

for these predicates. However, there are also cases that suggest that differential interpretations are sometimes possible for Japanese DAs: ${ }^{8}$

(20) Heya-wa kinoo-yori atatamat-ta-ga, mada atatakak-u-nai. room-TOP yesterday-than warm-PAST-but still warm-NONPAST-NEG

'The room has become warmer than yesterday, but it's still not warm.'

(Danboo-o ire-te) heya-ga sukosi atatamat-ta-ga, mada heater-ACC turn.on-TE room-NOM a little warm-PAST-but still atatakak-u-nai. warm-NONPAST-NEG

'(By turning on the heater,) the room has become warmer, but it's still not warm.'

Reisui-ga 3-do atatamat-ta-ga, mada atatakak-u-nai cold.water-NOM 3-degree warm-PAST-but still warm-NONPAST-NEG

'The cold water became cooler by 3 degrees, but it's still not warm.'

In these examples, atatamaru receives a differential interpretation ('become warmer') just like English DAs, and hence the entailment to the positive form is lost. But note crucially that all of these examples involve expressions that require explicit standards of comparison: the comparative yori phrase in (20), the degree modifier sukosi 'a little' in (21) and the measure phrase 3-do ' 3 degrees' in (22). What is common about these expressions is that they are all expressions that are incompatible with vague interpretations of gradable predicates. For example, it is independently observed that adjectives in Japanese are interpreted with respect to (either linguistically given or contextually determined) precise standards when they co-occur with these expressions (cf. Sawada \& Grano 2009 on measure phrases and Kubota to appear on yori phrases). Thus, these apparent counterexamples for the proposed analysis of DAs in fact provide further support for it: just as with adjectives, reference to a context-dependent vague standard is lost just in case there is additional linguistic material whose meanings are incompatible with vague predication.

One remaining issue that needs to be addressed is why, unlike adjectives (for which the specific standard, if not linguistically expressed, is provided by the context), the standard for the differential interpretation with DAs in (20)-(22) is always set to the initial degree. I assume that this is the case because of the nature of verbal predication: events denoted by DAs always have starting points. Thus, the degree that the object in question possesses at the initial state of the event is always salient in verbal predication, and, for this reason, if choosing a vague standard leads to

8 I would like to thank Takane Ito (p.c.) for pointing out these examples to me. 
semantic anomaly, this initial degree (which provides a fixed precise standard) is instead chosen to make the sentence interpretable. ${ }^{9}$

Interestingly, this analysis of Japanese DAs correctly predicts that the initial degree has to be zero with minimum standard predicates. The truth conditions for (3) is calculated as in (23).

$$
\begin{aligned}
& {[[\text { too-ga katamuk-u }]]=\lambda e . \text { slanted } \mid \Rightarrow(t)(e) \geq \operatorname{stnd}(\text { slanted })}
\end{aligned}
$$

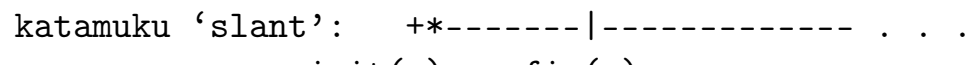

$$
\begin{aligned}
& \text { init(e) } \quad f i n(e)
\end{aligned}
$$

Just as above, the pos operator introduces the presupposition that the initial degree is below the standard, which, for minimum standard predicates, is the degree that is just above the zero point. But then, the only degree that is below the standard is the zero point, from which it follows that the only way in which (23) can be true is for the initial degree to be zero and the final degree to be above zero. This correctly captures the meaning of sentences like (6), repeated from above in (24):

\section{Too-ga katamui-ta. \\ Tower-NOM lean-PAST}

9 One might raise here a further question of why the differential interpretation is not the default one even without explicit expressions that are incompatible with vague standards. When vague and specific standards compete, it is generally the case that the specific standard wins. And this is precisely what Kennedy's (2007) Principle of Interpretive Economy predicts to be the case. Thus, one might think that the present analysis, which crucially makes use of the stnd function of the kind assumed in Kennedy (2007), would predict that only the differential interpretation is available for Japanese DAs. However, note one crucial difference between the case of standard setting for absolute (i.e., closed-scale) predicates (in which the specific standard wins over a vague one) and the case of DAs considered here. In the former case, the fixed absolute standard can be determined without reference to any context at all since it corresponds to one of the endpoints of the scale that is inherent to the lexical meaning of the predicate. In the latter case, the situation is different since the degree that the object in question possesses at the initial state of the event varies from one event to another and cannot be determined purely in reference to the meaning of the predicate. In such a case, Interpretive Economy does not favor either of the two standards over the other. But then, it is not totally unreasonable to think that the vague standard is preferred since that is after all the standard that is employed in adjectival predication (which, in the present analysis, constitutes the core meaning of Japanese DAs).

There is some evidence that suggests that the preference for the vague standard is in fact a preference rather than something that is hard-wired in the meaning of the predicate: there seems to be some variation regarding the availability of the differential interpretation both among predicates and among speakers. Judgments are somewhat subtle, but according to my own intuitions, predicates such as takamaru ('highten'), hikumaru ('lower'), tuyomaru ('strengthen') and yowamaru ('weaken'), which by themselves only designate the directions of degree change (one might call these verbs 'DA light verbs') and which usually occur with other expressions that further specify the nature of the relevant scales seem to allow for the differential interpretations more readily than other DAs with richer lexical contents. 
Marking aspect along a scale: -Te iku and -te kuru in Japanese

'The tower slanted.'

This sentence is true just in case the tower was completely straight initially and then acquired some amount of slantedness, not when the tower was already slanted and acquired some further amount of slantedness.

\subsection{The meanings of -te iku and -te kuru}

We are now ready to analyze the meanings of the two aspectual markers.

\subsection{1 -Te iku}

I assume that -te iku produces a derived minimally (but not maximally) closedscale predicate out of a DA in Japanese (which has the same scale structure as the corresponding adjective). This analysis can be formulated in the present setup by employing the notion of derived measure function, a device that K\&L crucially make use of in their analysis of DAs in English. The meaning of -te iku is given in (25):

$$
\left[[- \text { te iku }]=\lambda g \lambda x \lambda e \lambda t \cdot g_{g(x)(e)(\operatorname{init}(e))}^{\uparrow}(x)(e)(t)\right.
$$

(25) says that -te iku denotes a function that takes a (verbal) measure function (of type $\langle e,\langle e v,\langle i, d\rangle\rangle\rangle)$ and produces as output another measure function (of the same semantic type), where the input and the output measure functions differ in that the latter has a (derived) minimum endpoint corresponding to the degree that the object in question possesses at the initial state of the relevant event. As we will see below, this assumption alone (together with general and independently motivated assumptions about scale structure and standard setting) adequately accounts for all of the initially puzzling properties of the aspectual marker -te iku: (i) the (apparently noncompositional) loss of entailment to the positive form in the result state for open-scale and maximum standard predicates; (ii) the loss of the initial zero degree requirement for minimum standard predicates (which also apparently violates compositionality); and (iii) the emergence of variable telicity for maximum standard predicates (which does not exist in the lexical, unmarked form of these predicates).

Let us start with cases in which -te $i k u$ combines with open-scale predicates such as sameru 'cool'. The analysis for (5) (with -te iku) is given in (26):

$$
\begin{aligned}
& {[[\text { oyu-ga same-te iku }]]} \\
& =\lambda e \cdot \operatorname{cool}^{\uparrow} \operatorname{cool}(\mathbf{w})(\operatorname{init}(e)) \Rightarrow(\mathbf{w})(\operatorname{fin}(e))(e) \geq \operatorname{stnd}\left(\operatorname{cool}^{\uparrow} \operatorname{cool}(\mathbf{w})(\operatorname{init}(e))\right) \\
& =\lambda e \cdot \operatorname{cool}_{\Delta \mid \Rightarrow}(\mathbf{w})(e) \geq \operatorname{stnd}\left(\operatorname{cool}_{\Delta}\right)
\end{aligned}
$$


Yusuke Kubota
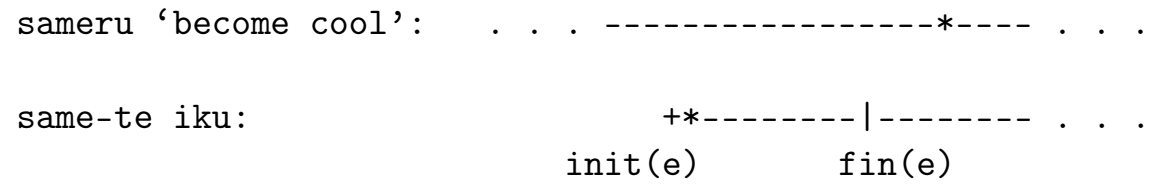

What is crucial here is that modifying the structure of the scale (from open to minimally closed) has the side effect of shifting the standard. Specifically, for the derived minimally closed scale, the standard is fixed to the context-independent degree that is just above the minimum endpoint of the (derived) scale. Consequently, the contextually determined vague standard of coolness associated with the original scale is lost. This explains why the entailment to the positive form in the result state is lost in the -te iku form. For (26) to be true, the temperature of the water merely needs to decrease from the initial degree without necessarily reaching the contextually determined standard of coolness.

Note that the proposed analysis correctly predicts that -te iku changes the telicity of DAs. The unmarked form of DAs in Japanese are telic since an event that makes (19) true is not homogeneous: its subevents that terminate before the standard is reached do not make the predicate true. By contrast, events that make (26) true are homogeneous since all of the subevents (down to minimal parts) of an event that makes (26) true satisfy (26) (since they all start somewhere on the scale of coolness and end at a degree that is higher than the initial degree). From this, it follows that the -te $i k u$ form of DAs are atelic.

Furthermore, the fact that the initial zero degree requirement is lost in the -te $i k u$ form of minimum standard predicates automatically follows from the proposed analysis. The analysis for (6) (with -te iku) is given in (27).

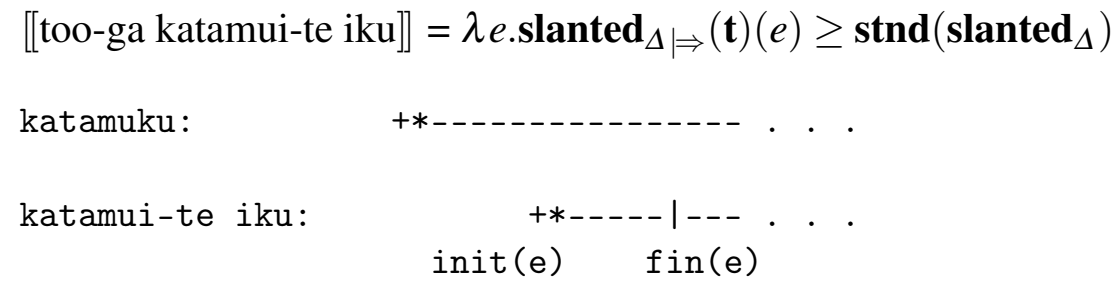

Here again, the crucial difference between the unmarked form and the -te iku form is that the standard is shifted from the original one due to the scale structure change. That is, the minimum endpoint of the derived scale is the degree of slantedness of the tower at the initial state of the event, which does not necessarily correspond to the zero degree of slantedness. (27) is true just in case a (possibly already slanted) tower increases its degree of slantedness, which is exactly what sentence (6) (with -te iku) means.

One might wonder how the telicity difference between the unmarked form and the -te $i k u$ form of minimum standard predicates is captured in the present analysis. 
As shown above, both are analyzed as involving minimally closed scales. But then, how is it that one is telic and the other atelic? The telicity difference between the two forms follows from an already observed property that distinguishes the -te $i k u$ form from the unmarked form: the loss of the initial zero degree requirement. That is, given the initial zero degree requirement, an event $e$ that satisfies (23) is not homogeneous since (assuming that $e$ is not minimal and has subparts) there is always $e^{\prime}<e$ such that the starting point of $e^{\prime}$ does not correspond to the zero degree on the scale, but (23) is not true of such $e^{\prime}$. (And if $e$ is minimal, it is atomic and is thus non-homogeneous.) From this, it follows that the unmarked form of minimum standard predicates is telic. By contrast, (27), even though it also involves a minimally closed scale, is crucially different from (23) in that it does not require the initial degree to correspond to the zero point of the original scale. (27) is true of any event in which the final degree of slantedness of the tower exceeds the initial degree. This means that, for any arbitrary event $e$ that makes (27) true, it is indeed the case that all of its subevents $e^{\prime}<e$ (down to minimal parts) also make (27) true, in other words, $e$ is homogeneous. Thus, the -te $i k u$ form of minimum standard predicates is atelic.

Finally, the emergence of variable telicity for maximum standard predicates in the -te $i k u$ form also automatically follows from the proposed analysis. The analysis for (7) (with -te $i k u$ ) is given in (28):

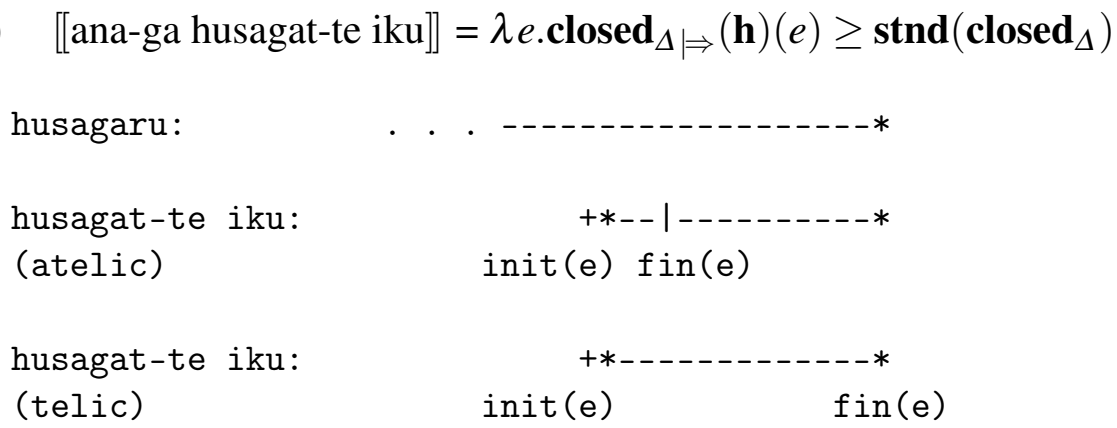

Imposing a minimum endpoint to a maximally closed scale produces a fully closed scale. In the typology of scale structure developed by Kennedy \& McNally (2005) and Kennedy (2007), for fully closed scales, there are in principle two ways in which the standard can be set: both the maximum and the minimum endpoints can be the target of standard setting. If the minimum endpoint is chosen, an atelic interpretation results which is true just in case there is some increase in the closedness of the hole from the initial degree. If, on the other hand, the maximum endpoint is chosen, a telic interpretation results which is true just in case the degree of closedness of the hole reaches the maximum endpoint. In this analysis, it is predicted that, for the telic 
interpretation for (7) to be true, the hole has to be completely closed in 30 days. This corresponds to the intuitively available reading of the sentence.

This analysis of variable telicity is essentially that of DAs in English by K\&L. What is initially puzzling about Japanese is that the unmarked form of the predicate is telic and the variable telicity emerges only with the addition of -te $i k u$. But this initial puzzle and the related puzzles of the loss of entailment to the positive form with open-scale predicates and the loss of the initial zero degree requirement for minimum standard predicates all disappear once we recognize the function of the aspectual marker -te $i k u$ as an operator that produces a derived minimum standard predicate out of DAs, which, in Japanese, are associated with scales whose structures are identical to those of their corresponding adjectives.

\subsection{2 -Te kuru}

Unlike -te iku, -te kuru does not change the telicity of the original DA. But the meaning (and entailment patterns) of the predicate changes. In particular, -te kuru seems to have some kind of attenuation effect so that the standard by which the truth conditional judgement is made is made less precise. Here, I will build on Sakahara's (1995) insight in formulating my analysis. The proposed analysis essentially says that -te kuru produces a derived predicate out of a DA, where the (only) difference between the original predicate and the derived one is that the scale for the latter is coarser-grained. I will show below that this analysis explicitly captures the telicity preserving effect of -te kuru as well as its attenuation effect.

Sakahara (1995) argues that the key property of -te kuru in its aspectual use is the expansion of the 'self territory' of the viewpoint taker. In the analysis of DAs in terms of scale structure, the notion of 'self territory' here can be thought to correspond to how narrowly (or precisely) the boundary of the standard point is carved out. As we will see below, expanding this boundary makes truth judgements less precise than otherwise and this has different effects on the truth conditions of sentences involving predicates with different scale structures. In the present setup where the aspectual marker -te kuru is analyzed as an operator on (verbal) measure functions, the meaning of -te kuru can be defined as follows:

$$
[[- \text { te kuru }]]=\lambda g \lambda x \lambda e \lambda t \cdot \operatorname{RedPrec}(g)(x)(e)(t)
$$

Here, RedPrec is a function that takes a measure function as an argument and returns another measure function where the (only) difference between the input and output measure functions is that the scale that the latter maps its arguments onto is made coarser than that for the former. ${ }^{10}$

10 Assuming that scales are modeled as ordered sets of degrees, this function can be defined by first restricting the range of the original measure function to its subset consisting of certain 'representative' 
Marking aspect along a scale: -Te iku and -te kuru in Japanese

For open-scale predicates and maximum standard predicates, reducing the granularity of the scale has the effect that the object in question is regarded as reaching the standard with a lower degree than otherwise. The analyses for (5) and (7) (both with -te kuru) are given in (30) and (31), respectively. ${ }^{11}$

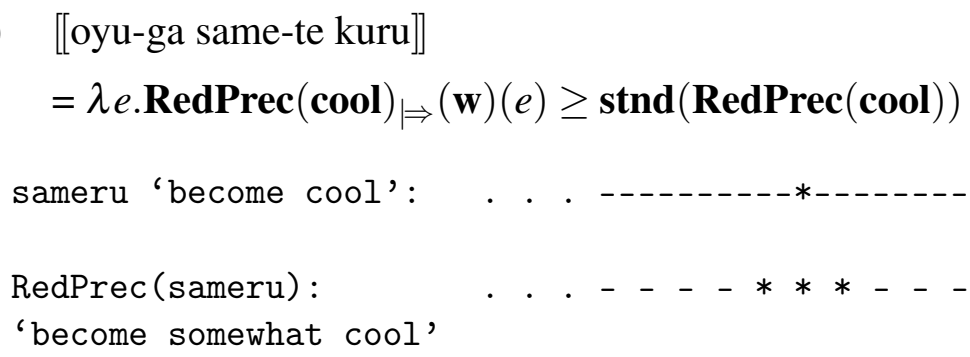

[[ana-ga husagat-te ki-ta $]=$

$\lambda e . \operatorname{RedPrec}(\text { closed })_{\mid}($the-hole $)(e) \geq \operatorname{stnd}(\operatorname{RedPrec}(\operatorname{closed}))$

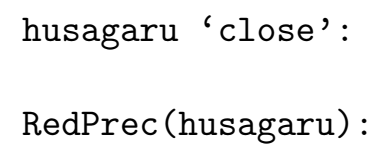

The present analysis correctly predicts that the entailment to the positive form is lost when -te kuru is attached to these predicates. Satisfying the standard with a less precise mode of measurement does not necessarily guarantee that the object in question satisfies the standard when a more precise mode of measurement is used. Note that this analysis does not encode the 'not reaching the standard' meaning of the -te kuru form of these predicates as semantic entailments. I assume, following Sakahara (1995), that this is an implicature arising from a Gricean economy principle of the kind discussed, e.g., in McCawley 1978 and Horn 1989 (in the latter under the rubric of 'division of pragmatic labor'). That is, in order to convey the meaning that the (precise) standard is reached, there is a simpler and less ambiguous form

degrees from the original set selected at a (contextually appropriate) even interval over the whole scale and then mapping objects in the domain to those degrees in the range of the output function that are closest to the degrees that these objects possess on the original scale. Working out the precise definition of this function requires making certain formal and ontological assumptions about degrees and scales specific. For example, scales are standardly model-led as an ordered set of real numbers, which is dense. However, in order to be able to talk about different degrees of granularity of scales, one will need to assume that scales are discrete rather than dense. Investigating these problems further and making the formal definition of the function RedPrec is an important issue, but since the primary focus of the present paper is empirical, I will not explore this technical issue here.

11 Relative predicates are by definition predicates that have vague, indeterminate standards. One might thus wonder whether reducing the granularity of the scale has any effect on the meaning of the predicate. This is an important issue, but due to space limitations, I will not address it here. 
(i.e., the bare form of these predicates). Thus, the existence of this alternative blocks the 'reaching the standard' meaning for the -te kuru form.

Note also that this analysis correctly captures the meaning difference between -te $k u r u$ and -te $i k u$ when they occur with open-scale and maximum standard predicates. -Te kuru-marked open-scale and maximum standard predicates entail that the degree in question comes close to the standard. In the present analysis, this is so because, for open-scale predicates and maximum standard predicates, requiring that the object in question meets the standard with a coarser grained scale is effectively the same as requiring that the degree comes close to the standard with the normal scale. -Te $i k u$, on the other hand, comes with no such entailment related to the standard of the original scale since its function is to convert the scale structure by imposing a derived minimum endpoint, which has the effect of resetting the standard.

Things are somewhat different for minimum standard predicates. As can be seen in (32), with minimum standard predicates, by making the scale coarser grained, the object in question has to have a larger degree than otherwise to count as satisfying the standard (= exceeding the minimum endpoint).

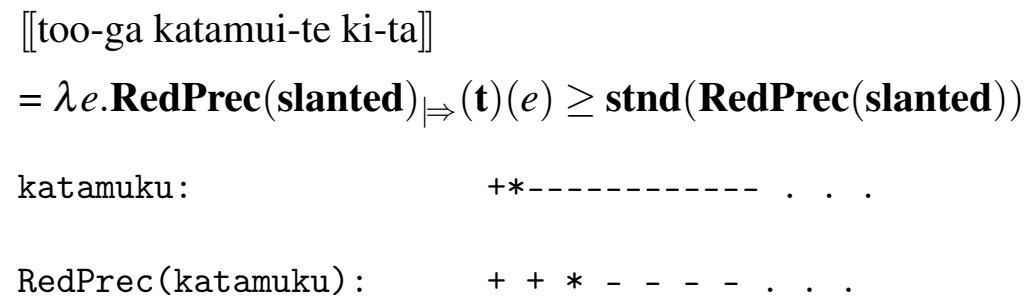

Thus, unlike with open-scale and maximum standard predicates, the entailment to the positive form is not lost with the -te kuru form of minimum standard predicates. Satisfying the standard with a less precise mode of measurement means that the object in question possesses a sufficiently large degree above the zero point, from which it follows that the normal standard is also satisfied.

The present analysis also correctly predicts that the -te kuru form preserves the initial zero degree requirement of minimum standard predicates. This is so because, unlike with -te $i k u$, the (endpoint-oriented) structure of the scale is not changed. Thus, the only way in which the predicate can be true is when the initial degree is zero and the final degree is above zero on the derived, coarser-grained scale.

Finally, the telicity-preserving effect of -te kuru is also correctly captured: -te kuru-marked predicates are still telic because RedPrec does not change the type of scale involved (i.e., open-scale, minimally and maximally closed). Since DAs in Japanese are telic change of state predicates, by attaching -te kuru, the whole predicate still denotes a bounded change of state event, and thus are uniformly telic.

That the proposed analysis of the meaning of -te kuru is on the right track can be further confirmed by the fact that -te kuru does not occur easily with degree modifiers 
Marking aspect along a scale: -Te iku and -te kuru in Japanese

targeting the maximum endpoint, an observation originally due to Sakahara (1995):
a. ?? Oyu-ga kanzen-ni same-te ki-ta.
hot.water-NOM completely cool-TE KURU-PAST
intended: 'The water (almost) became completely cool.'
b. ?? Too-ga kanzen-ni katamui-te ki-ta.
Tower-NOM completely lean-TE KURU-PAST
intended: 'The tower (almost) got slanted completely.'

\section{c. ?? Ana-ga kanzen-ni husagat-te ki-ta. \\ Hole-NOM completely close-TE KURU-PAST \\ intended: 'The hole (almost) closed completely.'}

This fact might initially appear puzzling given that a -te kuru-marked predicate is telic. But it is not really puzzling, considering the meanings of -te kuru and the adverb kanzen-ni 'completely': -te kuru's essential function is attenuation; kanzen-ni, on the other hand, is an adverb that asserts that the endpoint is unambiguously reached. But then, the meanings of -te kuru and kanzen-ni are inherently incompatible in that the adverb targets 'edgy' endpoints, whereas -te kuru's essential function is to make the endpoint blunt. The oddness of the examples in (33) is due to this semantic incompatibility.

\section{Conclusion}

In this paper, I have proposed an analysis of two aspectual markers -te iku and -te kuru in Japanese that crucially makes use of the notion of scale structure, building on the scale-based analysis of DAs in English by Kennedy \& Levin (2008). The proposed analysis cross-classifies the three forms of Japanese DAs in terms of two parameters of scale structure: (i) the presence/absence of a minimum endpoint corresponding to the initial degree in the event and (ii) the granularity of the scale involved:

\begin{tabular}{l|cc} 
& $\begin{array}{c}\text { initial degree as } \\
\text { minimum endpoint }\end{array}$ & reduced granularity \\
\hline base form & no & no \\
-te $i k u$ & yes & no \\
-te kuru & no & yes
\end{tabular}

The former parameter is taken by $\mathrm{K} \& \mathrm{~L}$ to be what distinguishes verbal gradable predicates (i.e., DAs) from adjectival ones in English, but if the results in the present paper are on the right track, languages differ from one another in whether they encode this distinction morpho-syntactically. 
The difference between Japanese and English DAs with respect to whether scale change is involved (in the unmarked form) might relate to a larger typological difference between the two languages. Recent work on other scalar predicatesspecifically, verbs with incremental theme arguments (Kennedy 2010) and the resultative construction (Uegaki 2010)—suggest that in English both constructions crucially involve measure of change functions that measure the (differential) degrees of the relevant property from the initial state of the event, in line with the analysis of DAs by K\&L. It is further suggested in Uegaki 2010 that Japanese resultatives differ from English ones in that the result phrases in Japanese do not introduce a minimally-closed measure function but merely define the endpoint of the event by means of a positive assertion of a gradable predicate (essentially in the same way that the predication of the base form of DAs in Japanese is treated in the present paper). Given these results on a wider range of phenomena, it is attractive to entertain the following hypothesis: English and Japanese contrast with one another in terms of whether the default way in which gradability (or incrementality) is introduced in the verbal domain is by means of (differential) measure functions. English is a language that extensively makes use of measure functions in the verbal domain across different constructions whereas Japanese is a language for which measuring incremental change by means of a measure function is not the default possibility: it is introduced only by means of an overt aspectual marker -te iku (which, in some sense, can be thought of as a counterpart of the comparative form of adjectives). In Japanese, verbal predication and adjectival predication are by default not distinguished in terms of scale structure. Whether such a typological distinction is justified needs to be examined with respect to a wider set of empirical phenomena. (A plausible candidate for this is motion/path constructions in the two languages.)

Also, the analysis of -te kuru that I have proposed in this paper crucially makes use of an operation that reduces the granularity of scales, but my proposal here remains at an intuitive level and is still tentative in its formal details. A possible further empirical application of such an operation would be the analysis of degree modifiers that have some kind of attention effects (e.g. English sort of and Japanese yaya and maamaa). If such an application yields successful analyses of a wider range of empirical phenomena, that will lend further support for the view that granularity of scale is another relevant parameter of scale structure. Investigating both the empirical and theoretical issues in this domain is yet another task for future research.

\section{References}

Beavers, John. 2010. Aspectual classes and scales of change. Ms., The University of Texas at Austin. 
Marking aspect along a scale: -Te iku and -te kuru in Japanese

Horn, Lawrence R. 1989. A natural history of negation. Chicago: Chicago University Press.

Imani, Ikumi. 1990. V-te kuru to V-te iku ni tsuite (On V-te kuru and V-te iku). Nihongo-gaku 9. 54-66.

Kennedy, Christopher. 2007. Vagueness and grammar: The semantics of relative and absolute gradable adjectives. Linguistics and Philosophy 30(1). 1-45. doi:10.1007/s10988-006-9008-0.

Kennedy, Christopher. 2010. The composition of incremental change. In Proceedings of 12th international symposium on Chinese languages and linguistics, Taipei: Academia Sinica.

Kennedy, Christopher \& Beth Levin. 2008. Measure of change: The adjectival core of degree achievements. In Kennedy \& McNally 2008, 156-183.

Kennedy, Christopher \& Louise McNally. 2005. Scale structure, degree modification, and the semantics of gradable predicates. Language 81(2). 345-381. doi:10.1353/lan.2005.0071.

Kennedy, Christopher \& Louise McNally (eds.). 2008. Adjectives and adverbs: Syntax, semantics and discourse. Oxford: Oxford University Press.

Kinsui, Satoshi. 2000. Toki-no hyoogen (Expressions of time). In Satoshi Kinsui, Mayumi Kudo \& Yoshiko Numata (eds.), Toki, hitei to toritate (tense, negation and focusing), Tokyo: Iwanami Shoten.

Kubota, Yusuke. to appear. Phrasal comparatives in Japanese: A measure functionbased analysis. In Olivier Bonami \& Patricia Cabredo Hofherr (eds.), Empirical issues in syntax and semantics, vol. 8. http://www.cssp.cnrs.fr/eiss8.

Lasersohn, Peter. 1999. Pragmatic halos. Language 75(3). 522-551. doi: $10.2307 / 417059$.

McCawley, James D. 1978. Conversational implicature and the lexicon. In Peter Cole (ed.), Syntax and semantics 9, 245-259. New York: Academic Press.

Piñón, Christopher. 2008. Aspectual composition with degrees. In Kennedy \& McNally 2008 183-219.

Sakahara, Shigeru. 1995. Fukugoo-dooshi V-te kuru (The compound verb V-te kuru). Gengo, Joohoo, Text 2. 109-143.

Sawada, Osamu \& Thomas Grano. 2009. Investigating an asymmetry in the semantics of Japanese measure phrases. To appear in Berkeley Linguistics Society (BLS) 35.

Sugioka, Yoko. 2009. Keiyooshi-kara tsukurareta dooshi (Adjectives made out of verbs). In Taro Kageyama (ed.), Keiyooshi, fukushi-no imi to koobun (Meanings of and constructions with adjectives and adverbs), 191-222. Tokyo: Taishukan.

Uegaki, Wataru. 2010. Cross-linguistic variation in the lexicalization of scalar change: The case of English and Japanese resultative constructions. MS., The University of Tokyo. 
Watanabe, Seiji. 2008. Nihongo-no hojodooshi -te iku -te kuru-ni tsuite (sono 1): - Te Iku-no asupekuto-sei-o chuushin-ni (Compound verbs -te iku and -te kuru in Japanese (1): Focusing on the aspectual properties of -te iku). Kassui Ronbunshuи 51. 69-91.

Yusuke Kubota

University of Tokyo, JSPS

yk@phiz.c.u-tokyo.ac.jp 